\section{Treating scar tissues during endoscopic submucosal dissection for gastrointestinal neoplasms}

The extensive fibrosis in gastrointestinal neoplasms with severe scarring often makes endoscopic submucosal dissection (ESD) difficult and unsafe to perform. The submucosal fibrosis prevents the mucosa layer from lifting during injection. In addition, the vessels in scar tissues are sometimes extensive and barely visible. Moreover, the scar tissue is hard to cut with a standard endoscopic electrosurgical knife. Therefore, ESD for this type of lesion results in more complications, and is associated with a lower en bloc resection rate. Here, we describe a trick for dissection of these fibrotic tissues. A flat lesion was found near the cardia after previous endoscopic resection ( $\mathbf{F i g . 1}$ ). The biopsy demonstrated high grade intraepithelial neoplasia. The ESD was started at the nonscarring site to create a wider submucosal layer for dissection before exposing the scar ( Fig.2). A Coagrasper (FD-411UR; Olympus, Tokyo, Japan) was then used to grasp the fibrotic tissue. Using the electrosurgical generator (ESG-100; Olympus), a soft coagulation mode at $80 \mathrm{~W}$ was used briefly to coagulate the vessels in the fibrosis, and subsequently a pulse-cutslow mode at $40 \mathrm{~W}$ was used to resect the tissue ( Video $\mathbf{1}$ ). The process was repeated to dissect the remaining fibrosis (๑ Fig.3).

\section{Video 1}

Dissection of fibrotic tissues using a Coagrasper (Olympus, Tokyo, Japan) during endoscopic submucosal dissection.
A colonoscope type of Coagrasper was favored because its smaller jaws might easily reach the narrow scarring submucosal space and decrease the thermal damage to the surrounding tissues. As the scissors type knives are still unavailable outside of Japan, we suggest that the method described here would be useful for lesions with severe fibrosis.

\section{Endoscopy_UCTN_Code_TTT_1AO_2AG}

\section{Competing interests: None}

\section{Peng Jin, Jian-qiu Sheng, Dong-liang Yu, Kuang-I Fu}

Department of Gastroenterology, Beijing Military General Hospital, Beijing, China

\section{Bibliography}

DOI http://dx.doi.org/

10.1055/s-0034-1377439

Endoscopy 2014; 46: E420

(C) Georg Thieme Verlag KG

Stuttgart · New York

\section{Corresponding author \\ Kuang-I Fu, MD}

Department of Gastroenterology Beijing Military General Hospital

Nanmenchang 5\#

Dongcheng District

Beijing 100700

China

Fax: +86-10-66721299

fukuangi@hotmail.com
ISSN 0013-726X

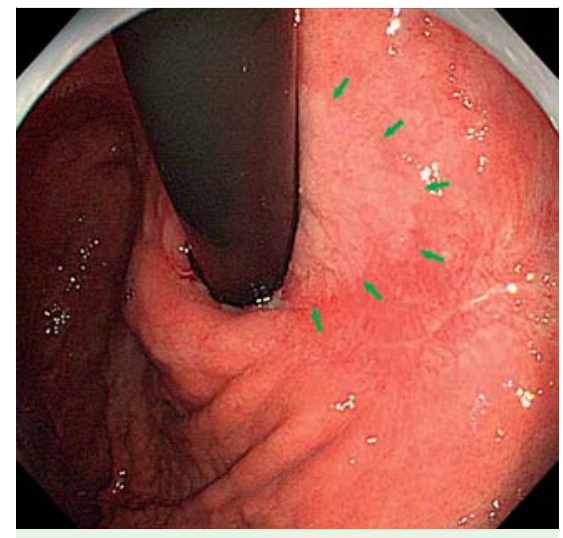

Fig. 1 A flat lesion near the cardia recurred after previous endoscopic resection (green arrows showed the margin).

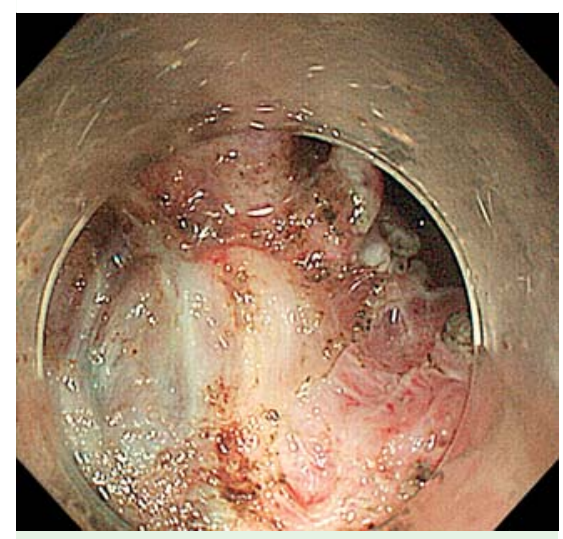

Fig. 2 The submucosal scar was exposed during endoscopic submucosal dissection.

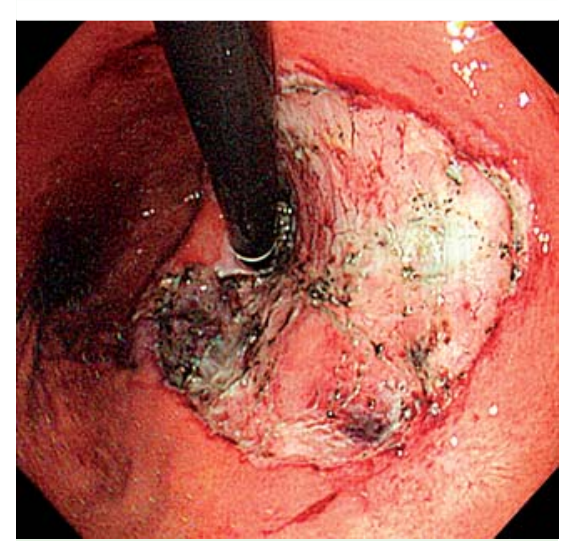

Fig. 3 Wound surface after completed endoscopic submucosal dissection. 